\title{
How US Withdrawal Might Influence Cooperation under the Paris Climate Agreement
}

Pre-print version

Cite as:

Sælen, H., Hovi, J., Sprinz, D.F., \& Underdal, A. (2020). How US withdrawal might influence cooperation under the Paris Agreement. Environmental Science \& Policy 108: 121-132.

Håkon Sælen (corresponding author)

CICERO Center for International Climate Research

P.O. Box 1129 Blindern, 0318 Oslo, Norway

+4722004723

hakon.salen@cicero.oslo.no

Jon Hovi

Department of Political Science, University of Oslo, Oslo, Norway

Detlef Sprinz

PIK - Potsdam Institute for Climate Impact Research \& University of Potsdam, Potsdam, Germany

Arild Underdal

CICERO Center for International Climate Research; Department of Political Science, University of Oslo

Funding:

This work was supported by CICEP: Strategic Challenges in International Climate and Energy Policy, Research Council of Norway project no. 209701.

Keywords:

Climate Change; Paris Agreement; President Trump; $2^{\circ} \mathrm{C}$ target; Agent-based modeling; Reciprocity 


\section{Introduction and literature review}

The Paris Agreement (UNFCCC 2015) is widely considered as a breakthrough in climate diplomacy. Its centerpiece is the collective goal to limit warming "to well below $2{ }^{\circ} \mathrm{C}$ above pre-industrial levels and to pursue efforts to limit the temperature increase to $1.5^{\circ} \mathrm{C}^{\prime \prime}$ (Rajamani and Guerin, 2017). The core, legally binding, commitment is to regularly prepare and report on Nationally Determined Contributions (NDCs) towards achieving these collective temperature goals (Brun, 2016). However, the submitted first-round NDCs fail to put emissions on a path consistent with limiting warming to $2^{\circ} \mathrm{C}$ (UNFCCC, 2015; Fawcett et al, 2015; Rogelj et al, 2016; Höhne et al, 2017). Therefore, that goal will be achieved only if the Paris process produces a cycle of increasing ambition. How to facilitate such a cycle was a central negotiation topic in Paris and remains so in on-going negotiations on implementation.

An adverse event occurred in June 2017, when President Trump announced the intention to withdraw the United States and vowed to cease domestic implementation immediately. To what extent will US withdrawal undermine the viability of the Paris architecture? And which elements of this architecture are most important for the effect of a US withdrawal?

To answer these questions, we use an agent-based model designed specifically to capture the basic dynamic elements of the Paris Agreement. Based on real-world data concerning each party's emissions and current NDC, this model includes 162 actors (the EU28 is treated as a unitary actor). It derives trajectories for future NDCs and emissions under different assumptions about factors such as actors' willingness and ability to comply, their inclination to reciprocate other Parties' actions, and their confidence in the institutions established by the Paris Agreement.

Literature on the US exit from the Paris Agreement is still sparse. Kemp (2017) suggests that, on balance, withdrawal by a reluctant US from the Paris Agreement might serve climate change mitigation better than a reluctant US remaining a member would. Urpelainen and van de Graaf (2017) argue that the US exit need not constitute an immediate threat to the pledge-and-review 
system; however, they are concerned that retraction of US climate finance could derail efforts to increase global mitigation ambition in the long run. Similarly, Pickering et al. (2017) highlight the risk of more defections (Turkey, Indonesia, and Saudi Arabia being likely candidates) as well as the option for countries to reduce their ambition concerning mitigation, while noting the possibility that countries remaining within the Paris Agreement could also upgrade their commitments in response to the withdrawal by the US. Chai et al. (2017) find that the US withdrawal will curtail emission reductions by $8.8-13.4 \%$ and will substantially reduce international finance for climate action, yet feedback by other countries is omitted from this national-level assessment. The paper that probably comes closest to ours is that of Sanderson and Knutti (2017), who use a "simple climate model ensemble" (p. 92) to estimate how the US withdrawal might influence the likelihood of meeting the collective temperature goal. However, their model does not specify the different elements of the political-economic cooperation process envisioned by Paris. Rather, it simply considers how the US withdrawal might influence a smooth pathway in which $\mathrm{CO}_{2}$ emissions first peak and then decline toward a long-term emission floor. Hence, while useful for their purposes, Sanderson and Knutti's model is less appropriate for studying what parts of the climate cooperation process are particularly vulnerable to US withdrawal. Finally, Sprinz et al. (2018) model the effect of US absence on the potential for minilateral cooperation in climate clubs, without considering the Paris institutions. Lack of US leadership is found to be a significant constraint on such clubs, while it makes less difference whether the US acts as a potential follower or as a laggard.

To our knowledge, we are the first to analyze the broader consequences of US withdrawal for the dynamic cooperation process envisioned by Paris. This process will include components such as progressively more ambitious NDCs, compliance rates, transparency measures, global stocktakes, and the member countries' confidence in the process. The agreement's eventual success (or failure) will likely depend on how such factors develop over time. Understanding these developments' driving forces is therefore important. This paper aims to contribute towards such understanding, using an agent-based model specifically designed to mimic the Paris cooperation process. 


\section{Method}

The ambition cycle envisioned under the Paris Agreement constitutes a dynamic process in which Parties adjust their ambition in response to the observed and promised behavior of others. For modeling such adaptive systems, agent-based modeling is a suitable method (Miller and Page 2009). Agent-based models are "computerized simulations of a number of decision-makers (agents) and institutions that interact through predescribed rules" (Farmer and Foley 2009). In our model, the agents are states (and the EU), while the institutions are interpretations of (specific aspects of) the Paris Agreement. In describing our model, we start with the institutions.

\subsection{Model institutions}

Taken together, the Paris Agreement and the accompanying COP Decisions (UNFCCC 2015) established the basic elements of a contribution cycle, with more detailed rules and procedures adopted at COP24 in 2018. Our model mimics this institutional architecture as outlined below.

\subsubsection{NDC cycle}

Article 4.9 requires Parties to communicate an NDC every five years. The first NDCs were communicated in 2015, and new ones are due in 2020 and then every five years thereafter (Decisions 23 and 24). Most first-round NDCs contain goals for 2030, although some contain goals for 2025. Parties with 2030 targets are requested to confirm or revise them in 2020 (Decision 24). From 2031, there will be common time frames, but its length has not yet been agreed (UNFCCC 2019a, 17). The model assumes a common time frame of five years so that NDCs submitted in year $t$ address emissions in years $t+6$ through $t+10$. Those five years are termed a contribution period (Figure 1).

\subsubsection{Emissions trading}

Opening up for "the use of internationally transferred mitigation outcomes towards [NDCs]," Article 6 suggests a Party may finance emissions reductions in another Party's territory and count them as part of the fulfilment of its own NDC. Negotiations on the rules and procedures could not be agreed as scheduled in 2018 and are still ongoing (UNFCCC 2019a). Allowing for trading could cut the global costs of achieving NDCs in half (Hof et al. 2017). Our model also allows for transfers and does not 
distinguish such mitigation arrangements from strictly domestic mitigation. Thus, a Party's total contribution is not capped at $100 \%$ of its own (2020) emissions.

\subsubsection{Progression principle}

Each new NDC "will represent a progression beyond the Party's then current [NDC]" (Article 4.3).

While this formulation leaves some room for interpretation, the model implements it as a requirement that each Party's NDC be no less ambitious than its previous NDC, measured as annual tonnes of GHG reductions. Thus, Parties who would otherwise lower their ambition are forced to keep it constant. This is a strict and probably overly optimistic interpretation of this "progression principle". Furthermore, it remains unclear whether this Article is legally binding and, if so, whether it can be enforced. We therefore run the model under two different assumptions, one where the Parties respect the progression principle and one where they ignore it.

\subsubsection{Annual reductions}

The model indexes emissions so that 2020 levels equal 100\%. Moreover, NDCs are specified in percentage points (pp) reductions relative to 2020. The model specifies NDCs as emissions reductions within a five-year contribution period, expressed as pp of the given Party's 2020 emissions (we explain the estimation of 2020 emissions in the next section). Consider a Party with initial emissions of 100 Megatonnes (Mt) pledging to reduce emissions to $95 \mathrm{Mt}$ by 2025 and to $87.5 \mathrm{Mt}$ by 2030 . Then, its first NDC takes the value $5 \mathrm{pp}$, while the second takes the value $7.5 \mathrm{pp}$. NDCs are converted into annual contributions for the five-year contribution period, assuming a linear trend.

\subsubsection{Negative emissions}

When a country has delivered $100 \mathrm{pp}$ cumulative reductions, its emissions equal 0 . The analysis includes model runs where some countries achieve negative emissions, which could be done either through negative emissions technologies, or - perhaps more realistically - by financing emissions reductions in other countries. Scenarios with negative global emissions are not included. Particular attention is given to the conditions under which global emissions reach zero before exhausting the emissions budget derived from the Agreement's $2^{\circ} \mathrm{C}$ target by Goodwin et al. (2018). 


\subsubsection{Reporting and reviewing}

Article 13 establishes a transparency framework. Parties shall report their emissions and information necessary to track progress in their NDC implementation and achievement biennially starting from 2024 (UNFCCC 2019b, 18). In the UNFCCC accounting framework, emissions reports typically contain data for the year $t-2$ or earlier (Briner and Moarif 2016). In the model, the 2024 report thus contains data on the first two years of implementation (2021 and 2022), and so forth. Article 13 also states that reports shall undergo a multilateral review. It will consist of a technical expert review followed by a multilateral consideration of progress (UNFCCC 2019b). The secretariat shall commence preparation of the review immediately after a transparency report has been submitted (UNFCCC 2019b). The model assumes the review will be completed the year after the report's submission, so the first review is completed in 2025, and will provide information on whether parties' actions and emissions in $2021(t-4)$ and $2022(t-3)$ are consistent with their NDCs.

\subsubsection{Global Stocktake}

The transparency framework focuses on individual Parties, and will not suffice for assessing aggregate progress (Briner and Moarif 2016; Rajamani 2016). Collective progress towards achieving the Agreement's goals will be assessed in global stocktakes every five years, starting in 2023 (Article 14). In preparation of their next NDC, parties shall explain how it has been informed by the outcomes of the stocktake (UNFCCC 2019a). The Stocktakes shall inform Parties in updating and enhancing their actions. In the model, the first stocktake assesses progress made in 2021 and 2022, while subsequent stocktakes assess progress during the five years following the previous stocktake. 
Figure 1: Interpretation of the process established by the Paris Agreement

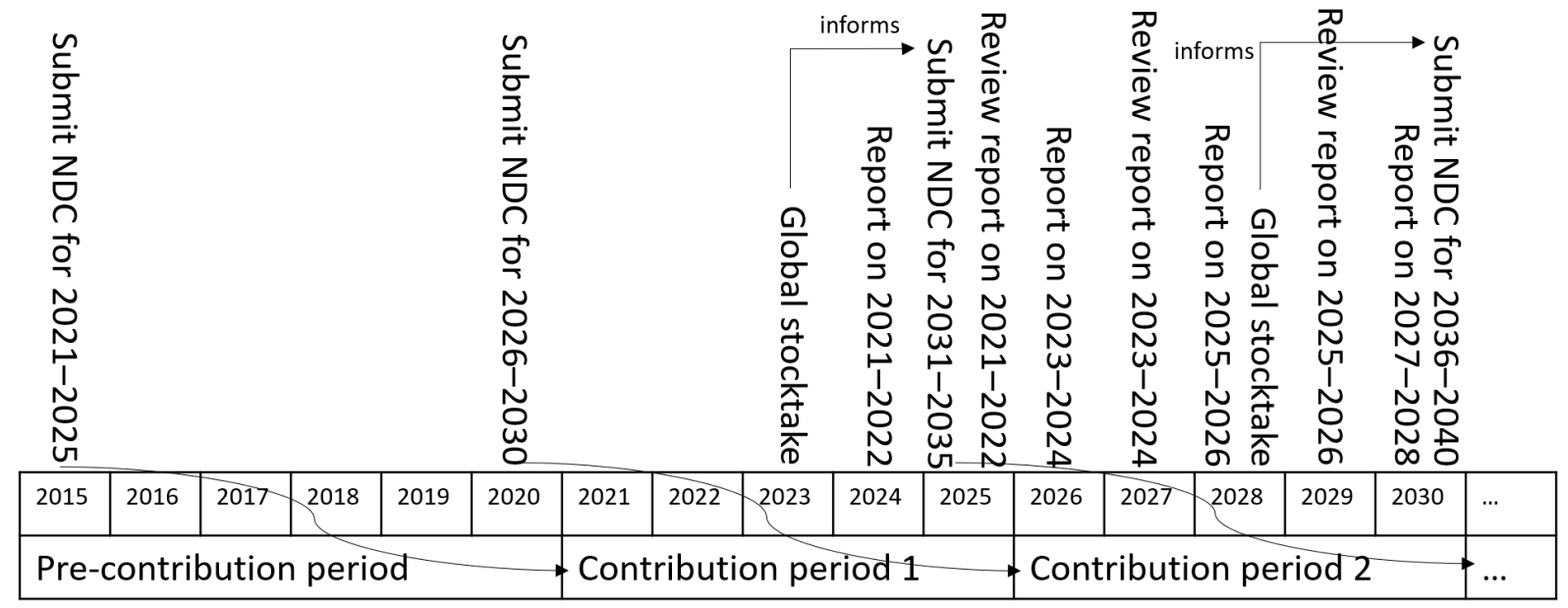

\subsection{Model actors}

The Paris Agreement has been signed by 195 countries. ${ }^{1}$ Due to lack of data, six small countries are excluded from the analysis. Because the EU countries have a joint NDC, we model the EU as a single actor. The model therefore contains 162 actors, responsible for virtually all global anthropogenic emissions - excluding international aviation and shipping.

Actors' initial emissions are calibrated on data from 2015 (Gütschow et al. 2018). Concerning emissions from land use change, we apply the 2011-2015 average, to limit the effect of inter-annual volatility. We assume that countries' emissions remain unchanged between 2015 and 2020, when implementation of the Paris Agreement starts.

\subsubsection{NDCs}

Because NDCs take a variety of formats and are described ambiguously, translating them into emissions is no trivial task. The analysis builds on three sources (Holz et al. 2017; Meinshausen and Alexander 2016; PBL 2017). Each source provides a high-emissions estimate and a low-emissions estimate, for three reasons. Some NDCs are formulated explicitly as a range, while for others, the

\footnotetext{
${ }^{1}$ Eight signatories have yet to ratify the Agreement (http://unfccc.int/paris agreement/items/9444.php [Last access Feb. 21, 2020]) and are thus not yet Parties. Their submissions therefore have the status of Intended Nationally Determined Contributions. For simplicity, we nevertheless use "Parties" and "NDCs" throughout.
} 
range arises in analysts' interpretation. In other cases, the high-emissions estimate refers to unconditional elements, while the low-emissions estimate includes also elements that are conditional on foreign financial assistance. We run the model for both emissions scenarios. For each country, the high/low scenarios are compiled by taking the mean across those of the three data sources that include this country. Global emissions in the period $2020-2025$ increase by $2 \%$ in the high-emissions scenario, and decrease by $2 \%$ in the low-emissions scenario.

Most Parties submitted NDCs with targets for 2030, and are thus required to confirm or revise them in 2020. The model assumes such updates affect annual contributions from 2026, while contributions until 2025 are determined by the NDCs already submitted, by taking the midpoint between estimated emissions in 2020 and targets for 2030.

First-round NDCs indicate every Party's initial willingness to contribute (IWTC). ${ }^{2}$ These IWTCs are central input parameters to the model. A Party's IWTC is defined as the percentage reduction in emissions by 2025, relative to current (2015) levels, implied by its NDC. For Parties whose NDCs imply increasing emissions, the score on this parameter will be negative. The model allows for the IWTC to be augmented in 2020 when Parties submit, revise, or confirm their 2030 targets, through the parameter Boost2020, applied uniformly to all Parties.

The analysis assumes that Parties, absent cooperation, would continue the trend set by their IWTC+Boost2020. Global emissions would thus increase from 2020 to 2100 by $38 \%$ in the highemissions scenario and decrease by $27 \%$ in the low-emissions scenario, given that Boost2020 is zero. These baseline scenarios imply lower emissions than the no-policy baseline scenarios included in the IPCC AR5 (Clarke et al. 2014, figure 6.5), where in the median scenario, 2100 emissions are $70 \%$ higher than 2020 emissions, while in the most optimistic scenario, they are roughly equal to 2020

\footnotetext{
${ }^{2}$ Input parameters to the model are denoted in bold while endogenous variables are italicized. Table A.1 lists and explains all parameters and variables.
} 
emissions. This assumption is consistent with the conclusion that current NDCs "with continued action" reduce emissions below AR5 no-policy baselines (Rogelj et al. (2017).

\subsubsection{Reciprocity}

For the Paris process to result in a positive cycle of ambition, Parties must reciprocate increasing contributions by others. The model varies the strength of such influence through a reciprocity parameter (RP) with values between 0 and 1, a concept introduced by Falk and Fischbacher (2005). For example, $\mathbf{R P}=.5$ means that if country A's perception of other Parties' contributions increases by $1 \mathrm{pp}$, its own willingness to contribute increases by $.5 \mathrm{pp}$. Because the RP parameter is unobservable and hence cannot be empirically calibrated, we vary it systematically across model runs. We also let it vary across countries, by drawing individual values from a uniform distribution with range 0.2 (except when the parameter is set at its minimum or maximum value). The average value across actors cannot exceed 1 (countries would then continually outbid each other, so the equilibrium willingness to contribute would approach infinity). The uniform function was chosen for its simplicity in lack of empirical data for calibration.

Although our model can accommodate both positive and negative reciprocity parameters, as well as a mix thereof, the current analysis excludes negative values, because - given the current model structure - it is trivial to predict that such values are not compatible with the Paris Agreement's goals. Hence, our model assumes contributions are strategic complements, which means states are in an Assurance game. This assumption is optimistic compared to many economic models of climate cooperation, which assume a Prisoners' Dilemma (PD) structure and predict that one country's unilateral ambition increase causes other countries to lower their ambitions (Hoel 1991; Buchholz et al. 1998; Holtsmark 2013; Konrad and Thum 2014). A PD structure would imply $\mathbf{R P}<0$ (contributions are strategic substitutes). On the other hand, the observed behavior of individuals is consistent with RP>0 (Croson 1996; Keser and Van Winden 2000; Fischbacher et al. 2001; Bardsley and Moffatt 2007; Kocher et al. 2008; Fischbacher and Gächter 2010). If reciprocity is widespread in the general population, it may be common among decision-makers in climate negotiations too, and if the median 
voter in a democracy has reciprocal preferences, a government motivated by re-election may act as if it has such preferences (Nyborg, 2018). Such assumptions may reverse the pessimistic prediction from existing models of cooperation (Buchholz and Sandler 2016, Nyborg 2018). The parameter could also capture other positive reinforcement mechanisms, as discussed in Author (2020).

Our model includes perceptions of what others have promised and delivered, with equal weight given to each. A country's promise is weighed by its credibility $(c r e d)^{3}$ and by its share of initial emissions $(\mathbf{e}) \cdot{ }^{4}$ The variable cred $_{i t}$ captures other countries' confidence that $i$ will comply with its new NDC, operating as a discount factor. This variable is updated through the review process described below. Perceptions of past aggregate contributions are based on the outcome of the previous stocktake (termed stock), ${ }^{5}$ also explained below. These assumptions result in a target function for NDC formulation:

$$
N D C_{i t}=\mathbf{I W T C}_{i}+\mathbf{R P}_{i}\left(\sum_{j \neq i}^{N-1} N D C_{j t} \times \operatorname{cred}_{j t} \times \mathbf{e}_{j 2020}+\operatorname{stock}_{i t}\right) / 2
$$

In summary, the target function contains two elements. The first is the IWTC, derived from the NDCs (and possibly augmented by Boost2020). The second-more complex-element is the reciprocation of others' contributions, which is a function of Parties' own propensity to reciprocate (RP) and their perception of others' contributions. The review and stocktake influence ambition through these perceptions. The target function approach reflects the findings of Fischbacher and Gächter (2010)

\footnotetext{
${ }^{3}$ The subscript $t$ here refers to the most recent review available at time $t$.

${ }^{4}$ Because NDCs are measured as pp reductions from 2020 emissions levels, they are weighed by emissions shares in 2020. Party i's emissions are excluded from the calculations of others' emissions shares, so that the weights sum to one.

${ }^{5}$ The subscript $t$ here refers to the most recent stocktake available at time $t$.

${ }^{6}$ This is a simplified equation which assumes NDCs are positive and that the progression principle is ignored. The more general equation is found in the Technical Appendix.
} 
that contributions in a repeated public good game can be modeled as a function of underlying preferences for, respectively, unconditional and conditional contribution, and beliefs about others' contributions.

The target function for country i's NDC for period $t$ includes others' $N D C s$ for period $t$; hence, the target functions are interdependent. The model portrays an idealized process of NDC formulation in which indicative $N D C$ s are adjusted iteratively until no country wants to change its NDC given all others' $N D C s .{ }^{7}$ The model converts each NDC into annual emissions reduction pledges, denoted $n d c$, assuming a linear trend over the five-year period.

\subsubsection{Compliance, confidence in review, and credibility}

Although we assume Parties intend to achieve what they pledge, thereby abiding by the Agreement's Article 4.2, Parties may accidentally fail to comply perfectly. The assumed probability of compliance varies across Parties, and is not directly observable by others. In year $t$, Party $i$ will reduce emissions \left.${\text { by } n d c_{i t}(\text { i.e., contribution }}_{i t}=n d c_{i t}\right)$ with probability Compliance rate ${ }_{i}$, otherwise it will keep emissions constant from year $t-1$ (i.e., contribution $n_{i t}=0$ ). If $n d c_{i t}$ is negative, and $i$ happens not to comply, it will emit $1 \mathrm{pp}$ more than pledged (i.e., contribution $\left.{ }_{i t}=n d c_{i t}-1\right) .{ }^{8}$ Deeper shortfalls are not considered.

The review process assesses Parties' compliance, and the outcome affects their credibility $\left(c r e d_{i}\right)$. Each review covers two years, and compliance in each year is binary, so the possible outcomes are compliance in zero, one, or two years. The review process will unlikely be perfect, so Parties may not completely trust the review outcome. Hence, a positive review is discounted by the parameter

\footnotetext{
${ }^{7}$ In order to limit computational requirements, and with negligible effect on results, NDCs are finalized when no country would want to change their indicative NDC by more than $.1 \mathrm{pp}$.

${ }^{8}$ The amount by which non-complying countries over-emit relative to NDCs is thus set somewhat arbitrarily, especially for negative NDCs. However, under the conditions conducive to staying within the $2^{\circ} \mathrm{C}$ budget, negative NDCs do not figure prominently and hence have limited influence on the main results.
} 
confidence in review (CiR), which takes values from 0 to 1. cred $_{i t}$ is a weighted average between cred $_{i t-1}$ and discounted compliance at time $t$. This incorporates Fischbacher and Gächter's (2010) finding that individual $i$ 's belief at $t$ is a weighted average of her belief about others at $t-1$ and her observation of others' contribution in the previous period. The weight given to the most recent review relative to ${ }^{\prime}$ 's credibility at $t-1$ is determined by a learning parameter (LP). As data for determining the weight is lacking, LP will be kept constant at .5 in the current analysis. After each review, a Party's credibility is updated according to the following formula

cred $_{i t}=\frac{\text { years in compliance }}{2} \times \mathbf{C i R} \times \mathbf{L P}+\operatorname{cred}_{i t-2} \times(1-\mathbf{L P})$

At the start, $\operatorname{cred}_{i}=0$, so until Parties see verified actions by others, their NDCs simply equal their IWTC. The extent to which the Paris process builds trust among Parties is captured by increases in

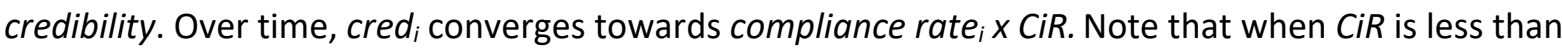
1 , credibility cannot reach 1 even with perfect compliance. If countries reduce emissions more than promised or believe the review underestimates actual emissions reductions ( $\operatorname{CiR}>1$ ), cred $_{i}$ could in theory exceed 1; however, we do not consider such scenarios.

\subsubsection{Confidence in Global Stocktake}

Perceptions about aggregate past progress are informed by the global stocktake. Again, Parties will unlikely completely trust that others have contributed as much as the stocktake indicates, so they discount the outcome by the parameter Confidence in stocktake (CiS), which takes values from 0 to 1. ${ }^{10}$ The perception by Party $i$ at time $t$ is given by:

$$
\text { stock }_{i t}=\sum_{j \neq i}^{N-1} \sum_{n=t-5}^{t-1} \text { contribution }_{j n} \times \mathbf{e}_{j 2020} \times \mathbf{C i S}
$$

\footnotetext{
${ }^{10} \mathrm{CiS}$ could exceed 1 if countries believe stocktakes underestimate actual contributions; however, we ignore such scenarios.
} 
Parties hence consider the sum of other Parties' contributions over the previous five years ${ }^{11}$ measured in pp of 2020 emissions. Note that because Paris does not mandate the stocktake to assess individual Parties, the outcome does not affect individual Parties' credibility.

\subsection{Model structure}

Figure 2 illustrates the model's relationships in a simplified version containing only two countries Blue and Red. Global processes and variables are shown in black. Solid arrows show effects of parameters on variables or of one variable on another. Dashed arrows denote effects on other relationships (interactions). NDC ambition in Red has a direct effect on NDC ambition in Blue, and the strength of this relationship is determined by red's credibility. Red's contributions also have indirect effects on Blue's NDC ambition (through the Global Stocktake) and on Red's own credibility (through the Review). The effectiveness of Global Stocktakes and Reviews is determined by the global parameters Confidence in Stocktake and Confidence in Review, respectively, which are not included in the figure. The Technical Appendix provides a complete explanation, including a list and explanation of all parameters and variables.

\footnotetext{
${ }^{11}$ Assessing only the years 2021 and 2022, the first stocktake in 2023 constitutes an exception.
} 
Figure 2: Simplified model cycle

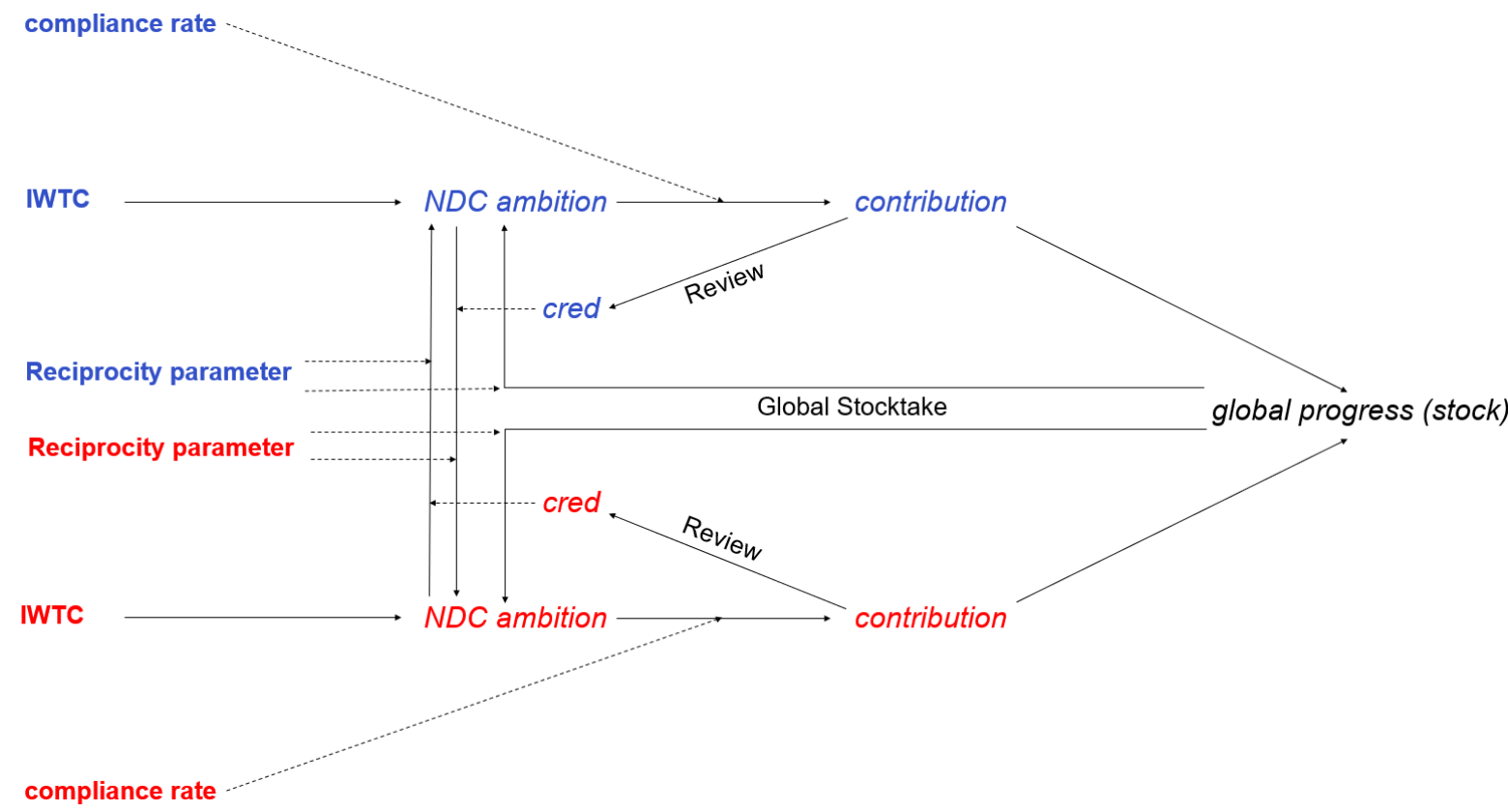

On June 1, 2017, President Trump announced that the United States intends to leave the Paris Agreement. Domestic and international climate policies have been contentious in the United States for decades, resulting in the unanimous 1997 Byrd-Hagel resolution passed by the US Senate to oppose US membership in any international climate agreement without substantive obligations for major emerging economies or that would otherwise hurts the US economy. While the George W. Bush administration rejected the Kyoto Protocol, the Obama administration aimed for an agreement that does not require the Senate's advice and consent.

Trump's announcement caused domestic US political disagreement, and some US governors who enjoy state-level support in favor of farsighted climate policies vowed to fulfil their share of the US NDC.

Through a sector-by-sector review, Galik et al. (2017) estimate that US emissions under the Trump administration will remain approximately constant at 2015 levels, regardless of whether the administration holds power for four or eight years. We consider two "treatments": In T1, Trump serves a single period, and in T2, he is re-elected in 2020. T1 and T2 are compared to a (hypothetical) baseline (TO), in which the United States remains in the Paris Agreement and acts like other Parties 
do. To isolate the effect of Trump's presidency, we assume Trump's successor immediately re-enters Paris and reverts to the Obama administration's ambition levels, measured in annual emissions reductions. We do not consider scenarios with more permanent non-participation or scenarios where the successor accelerates action to compensate for the Trump hiatus.

We assume that US behavior continues to affect others' behavior after it withdraws. The second largest emitter is modeled as a relevant player, even if not formally part of the Agreement.

Specifically, under T1, US emissions reductions are delayed four years, beginning in 2025 instead of 2021 as in the baseline (T0). Under T2, the delay extends to another contribution period, so that reductions begin in 2031. In other words, the delay in emissions reductions in T2 relative to T0 is 10 years. Post-Trump, the United States is - like other countries - assumed to set its subsequent NDC according to equation (1) during the next pledging procedure, that is, in 2020 under T1 and in 2025 under T2. The US IWTC is derived from the NDC submitted by the Obama administration. US credibility remains at zero until its first emissions reductions are reviewed, that is, until 2029 in T1 and until 2035 in T2. Thus, Trump also delays the building of US credibility by four years in T1 and by 10 years in $\mathrm{T} 2$.

In reality, a 10-year delay is not inevitable even if Trump is re-elected. His successor could submit a new NDC before the deadline in 2025 and start reducing emissions before 2031. Although limiting the delay to eight years might be possible, the time needed to reverse Trump's policies will likely be longer after two terms than after one, as captured by our chosen delay values of 10 and four years, respectively.

\subsection{Emissions budget remaining if the Paris Agreement's goal is to be achieved} The amount of greenhouse gas emissions that can be emitted without exceeding the $2^{\circ} \mathrm{C}$ target is subject to considerable uncertainty and debate. Using a novel approach to reducing uncertainty, a recent analysis estimates that meeting the $2^{\circ} \mathrm{C}$ target in $66 \%$ of scenarios implies that the budget remaining from the beginning of 2017 is $35-41$ times current annual emissions (Goodwin et al. 2018). 
This estimated budget is somewhat larger than most previous estimated budgets (e.g., (Global Carbon Global Carbon Project 2016; IEA 2016)). As our model assumes emissions remain at constant levels between 2017 and the beginning of 2021, we assume the remaining budget by 2021 is 31-37 times current annual emissions.

\section{Results}

The values of many of our input parameters are uncertain, therefore we run the model for multiple values of those parameters (Table 1, first two columns, top five rows). In total, the analysis reported here examines 1,054,152 different parameter configurations, distributed evenly across the six numerical columns. ${ }^{13}$ Moreover, the probability distributions for the parameters are also unknown, so we cannot assign probabilities to different model runs. However, by comparing our three treatments $(\mathrm{T} 0, \mathrm{~T} 1, \mathrm{~T} 2)$ while keeping other parameters constant, the Trump effect can be isolated. Figures 3-5 show this effect in a small selection of scenarios. Each figure shows the effect conditional on two binary input parameters. The top row uses the high-end estimate of emissions implied by the first-round NDCs (High), whereas the bottom row uses the low-end estimate (Low). The right-hand column assumes the progression principle is respected (Prog), while the left-hand column assumes that it is ignored (No prog).

\footnotetext{
${ }^{13}$ Because the model contains stochastic elements, results may vary somewhat between repeated runs with the same parameter configuration. We do not explore such variation here.
} 
Table 1: The parameter values included in the analysis and the minimum values observed in scenarios that stay within the upper-bound estimate for the $2^{\circ} \mathrm{C}$ budget.

\begin{tabular}{|c|c|c|c|c|c|c|c|}
\hline \multirow{3}{*}{ Model parameter } & \multirow{3}{*}{$\begin{array}{l}\text { Values } \\
\text { examined }\end{array}$} & \multicolumn{3}{|c|}{$\begin{array}{l}\text { Progression principle } \\
\text { respected }\end{array}$} & \multicolumn{3}{|c|}{$\begin{array}{l}\text { Progression principle } \\
\text { ignored }\end{array}$} \\
\hline & & TO & $\mathrm{T} 1$ & $\mathrm{~T} 2$ & TO & $\mathrm{T} 1$ & $\mathrm{~T} 2$ \\
\hline & & \multicolumn{3}{|c|}{ Minimum value observed } & \multicolumn{3}{|c|}{ Minimum value observed } \\
\hline Boost2020 & $0,1 p p, \ldots, 5 p p$ & 0 & 1 & 2 & 2 & 3 & 4 \\
\hline Compliance rate mean ${ }^{14}$ & $0, .1, \ldots, 1$ & .8 & .8 & .8 & .8 & .8 & .9 \\
\hline Reciprocity parameter mean ${ }^{13}$ & $0, .1, \ldots, 1$ & .2 & .3 & .5 & .2 & .3 & .5 \\
\hline Confidence in review & $0, .1, \ldots, 1$ & 0 & .3 & .4 & .2 & .4 & .6 \\
\hline Confidence in global stocktake & $0, .1, \ldots, 1$ & 0 & 0 & 0 & 0 & 0 & .1 \\
\hline \multicolumn{2}{|c|}{$\begin{array}{l}\text { Percentage of scenarios where the minimum } \\
\text { conditions are simultaneously met or exceeded }{ }^{15}\end{array}$} & 22.3 & 12.0 & 6.3 & 12.2 & 6.3 & 1.4 \\
\hline \multicolumn{2}{|c|}{$\begin{array}{l}\text { Percentage of scenarios that stay within the } \\
\text { upper bound } 2^{\circ} \mathrm{C} \text { budget estimate }\end{array}$} & .64 & .33 & .12 & .47 & .23 & .08 \\
\hline \multicolumn{2}{|c|}{$\begin{array}{l}\text { Percentage of scenarios that stay within the } \\
\text { lower bound } 2^{\circ} \mathrm{C} \text { budget estimate }{ }^{14}\end{array}$} & .17 & .06 & .01 & .10 & .03 & $<.01$ \\
\hline
\end{tabular}

In Figure 3, all remaining parameters are set at the midpoint of the examined range (see Table 1,

column 2). Under these settings, the Paris process fails to produce increasing ambition over time.

Instead, global emissions increase for the entire time period considered. The difference between the

High and Low scenarios is here large and increasing over time, although the progression principle

contributes somewhat to limiting the emissions increase. The effect of Trump is hardly discernable;

indeed, the Paris process fails regardless of US policies to reduce emissions long term.

\footnotetext{
14 Unweighted

15 The number of scenarios investigated in each column is 175,692 ( $1 / 6$ of the total).
} 
Figure 3: Development of global emissions. All other parameters at their midpoints (see Table 1).

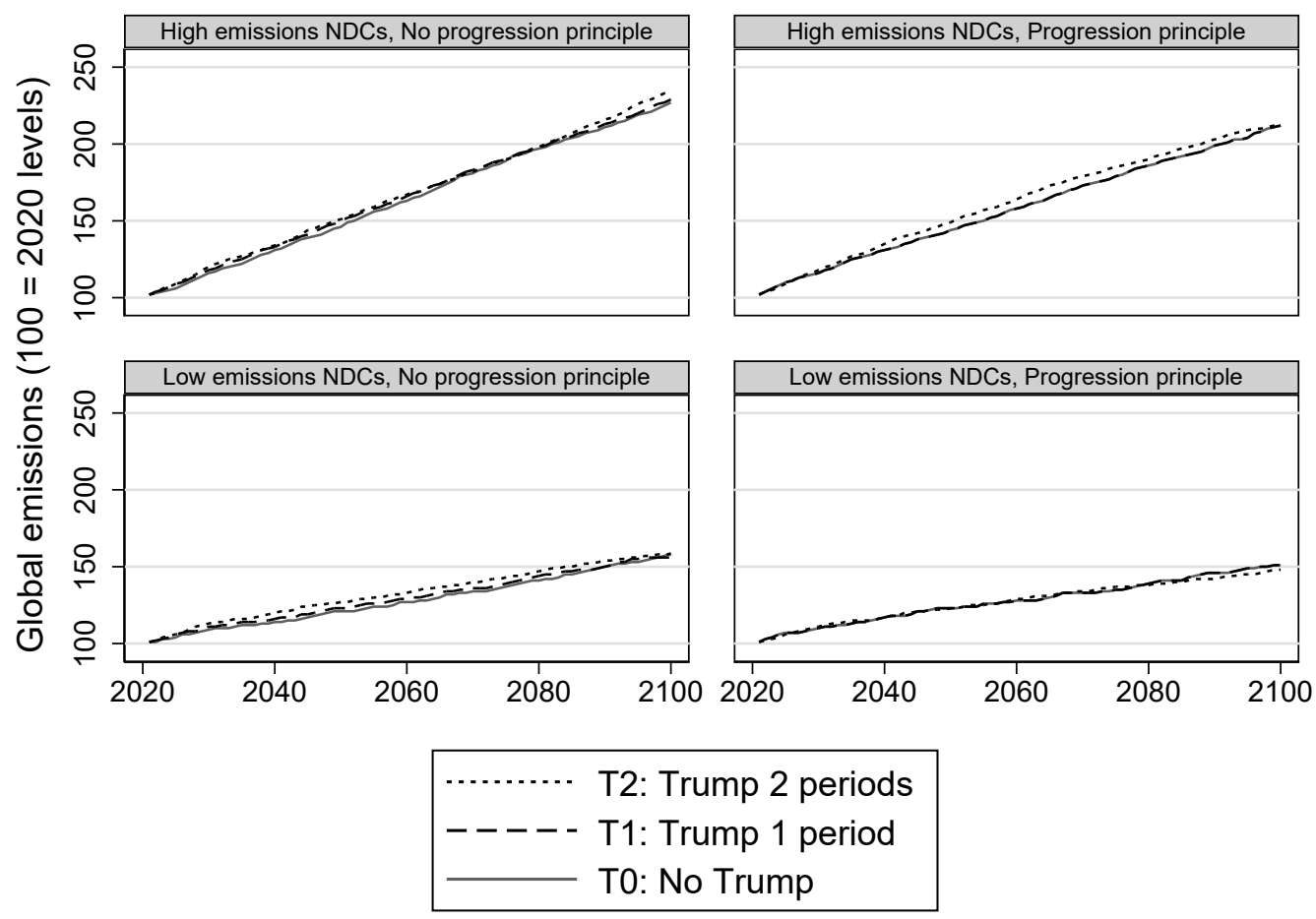

Figure 4 shows the results for more optimistic scenarios. Here, the other parameters are set at the second-highest value examined (i.e., Boost2020=4pp., all other parameters=.9). Now, the Paris process succeeds in generating increasing ambition, at least after some time. In the Low scenarios, global emissions reach zero well before 2100, while in the High scenarios, 2100 emissions are closer to current levels than to zero, after initially increasing. The progression principle has greater effect in the High scenarios than in the Low scenarios, because the latter contains few instances where any country would want to decrease its ambition in any case. In all four quadrants, the effect of Trump is much larger than in Figure 3, mainly because countries are now more responsive to the behavior of others including the United States. Moreover, the baseline (T0) from which Trump detracts is higher the more optimistic other settings are. Figure 4 also shows that the Trump effect persists and actually increases over time, because of positive feedback through the reciprocity mechanism. 
Figure 4: Development of global emissions. All other parameters at one notch below their maximum (see Table 1).

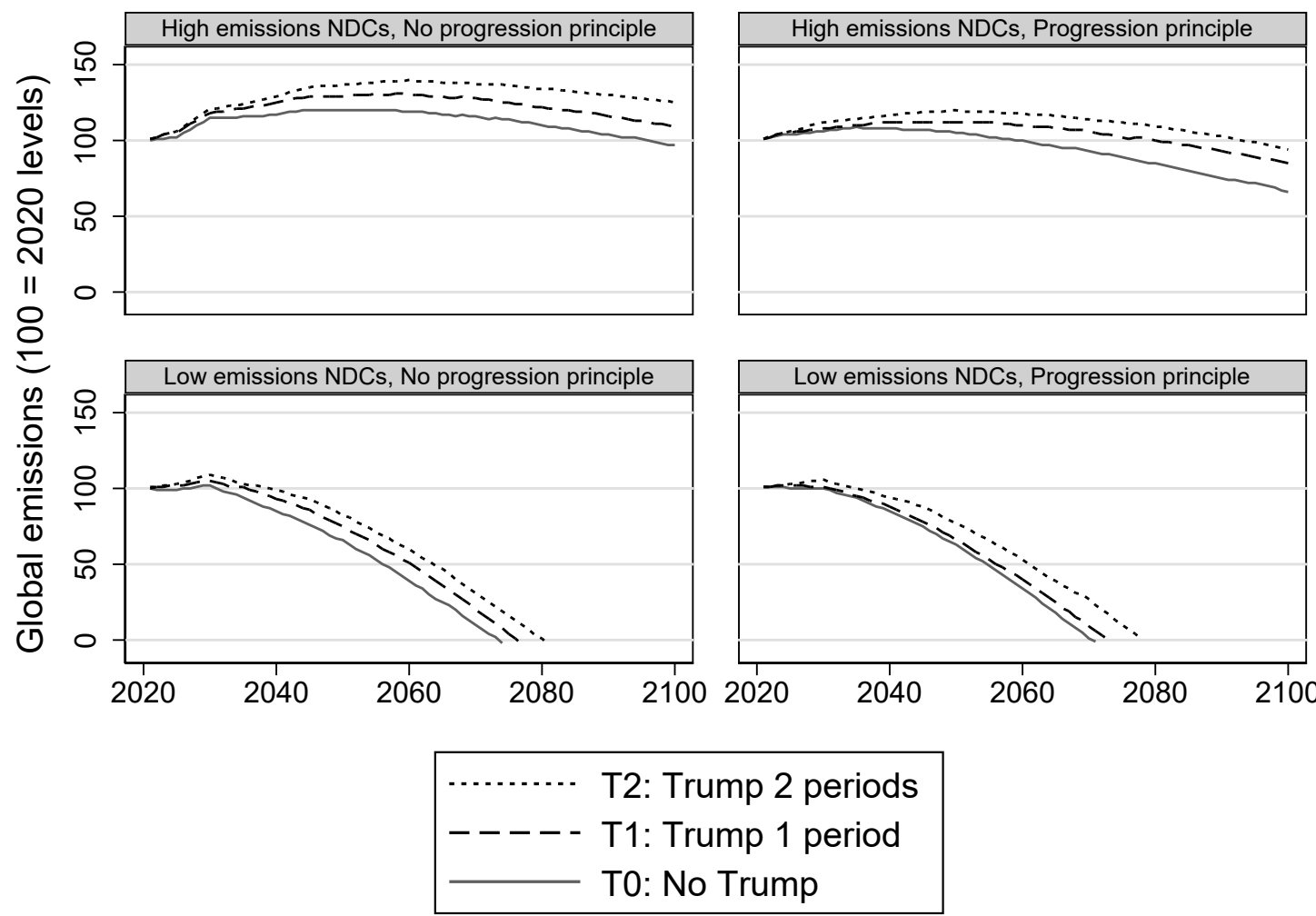

Figure 5 shows the sensitivity of Figure 4's lower-left scenario to variation in the Reciprocity parameter, confirming that high levels of reciprocity magnifies the long-term Trump effect. With this parameter at zero, Trump's effect on global emissions does not increase over time and is thus small in total (Figure 5, upper left). Figure 5 also illustrates that the rate of emissions reductions (i.e., ambition) only increases over time (concave trajectory) if the reciprocity parameter is very high. A very high reciprocity parameter is thus a necessary condition for the $2^{\circ} \mathrm{C}$ target to be within reach. Unfortunately, this is also the setting in which US withdrawal has the most detrimental effect. In contrast, in scenarios where actors are unresponsive to others' contributions (upper left), emissions will remain substantial in 2100 (even if well under half of their 2020 level). Here, US withdrawal will have no repercussions on other countries and will therefore have only limited effect overall. Hence, the three treatments do not differ very much. As the reciprocity parameter increases (upper right and bottom left), global emissions decline faster; however, the differences between the three treatments also increase, indicating a bigger Trump effect. Finally, with a very high reciprocity 
parameter (bottom right), global emissions could reach zero as early as 2080 , depending on

treatment. However, a very large reciprocity parameter also entails a large Trump effect; indeed, reaching zero global emissions will take around a decade longer with a two-period US withdrawal than without a US withdrawal. Hence, the initial 10-year delay in US emissions reductions eventually causes a 10-year delay in global emissions reductions. In contrast, in the other three quadrants the delay in global emissions reaching zero is considerably shorter.

Figure 5: Development of global emissions over time, by reciprocity parameter and treatment. All other model parameters at their second-highest value.

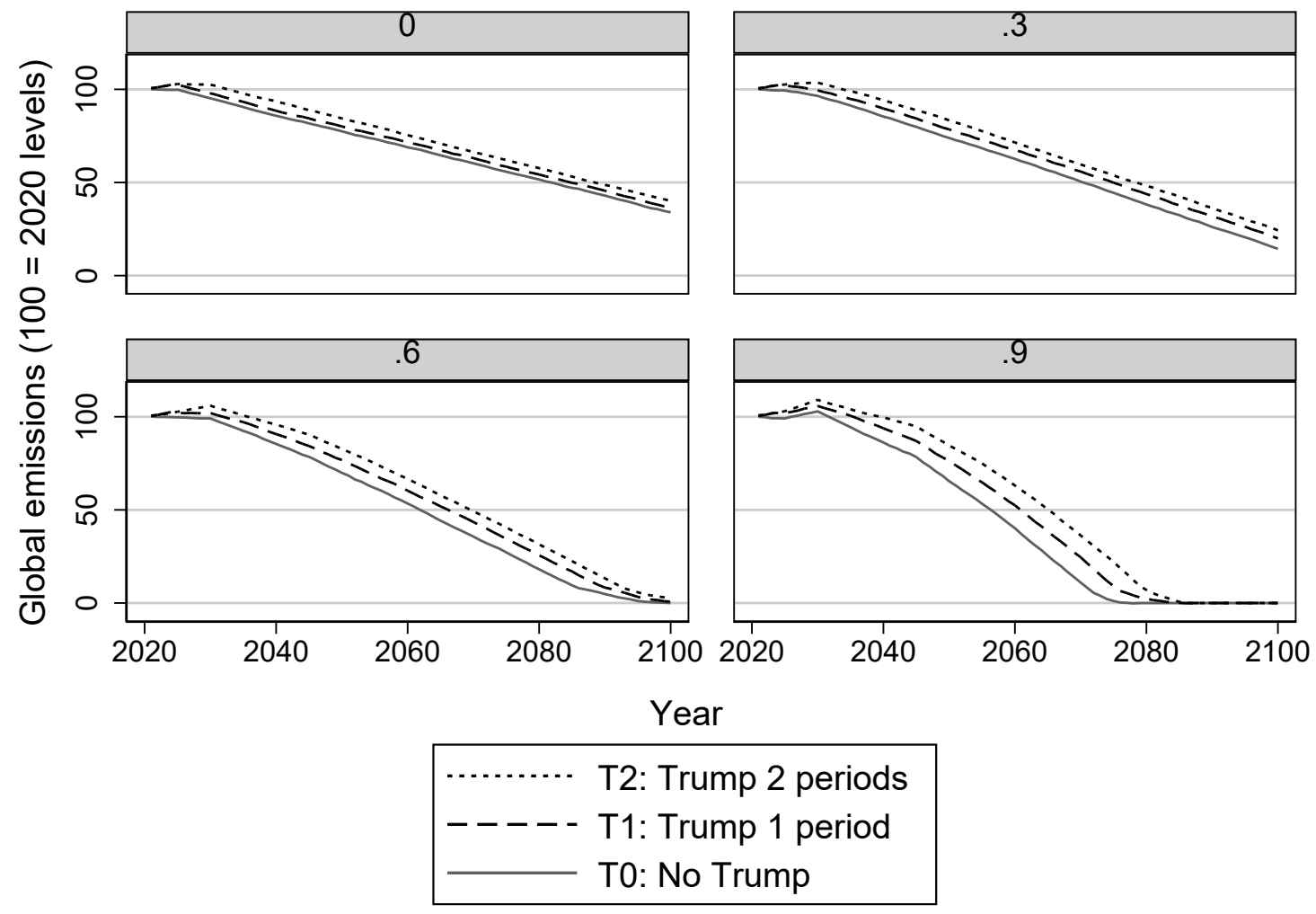

Figure 6 disaggregates the overall effect of US withdrawal into US emissions and emissions from the rest of the world (ROW) for the scenario in the bottom-left panel of Figure 4 (all other variables at their second-highest value). The figure shows that while the effect on US emissions is immediate, the effect on others' emissions is lagged and increasing over time. After some time, the effect on others' emissions exceeds the effect on US emissions. The delay may be explained by the processes illustrated in Figure 2. The effect of US behavior operates through other countries' NDCs, and it takes 
5-10 years from when NDCs are submitted until they are implemented (Figure 1). Furthermore, part of the US withdrawal's impact on others operates through the review and the global stocktake, which implies further delay and increasing effect over time. In general, the increasing effect over time occurs because of the model's positive feedback mechanism, whereby ambition breeds ambition. The US withdrawal triggers that mechanism in reverse.

Figure 6 also shows that the United States accounts for a large share of global emissions reductions in the long term, even under T1 and T2. US emissions become negative from around 2040, implying that the United States is either employing negative emissions technologies or financing large emissions reductions in other countries. These trajectories suggest that the United States' NDC is ambitious compared to other NDCs when measured in percent of 2015 emissions and extrapolated beyond the target year (2025). However, that starting point is very high for the United States, in both absolute and per-capita terms. Alternative ways of assessing Parties' relative ambition levels are discussed in Pan et al. (2017) and in Author et al. (2019 [this journal]).

Figure 6: Development of emissions in the United States (left) and the rest of the world (right) by treatment. All other model parameters at their second-highest value. (Note that simulations terminated when global emissions reached zero.)
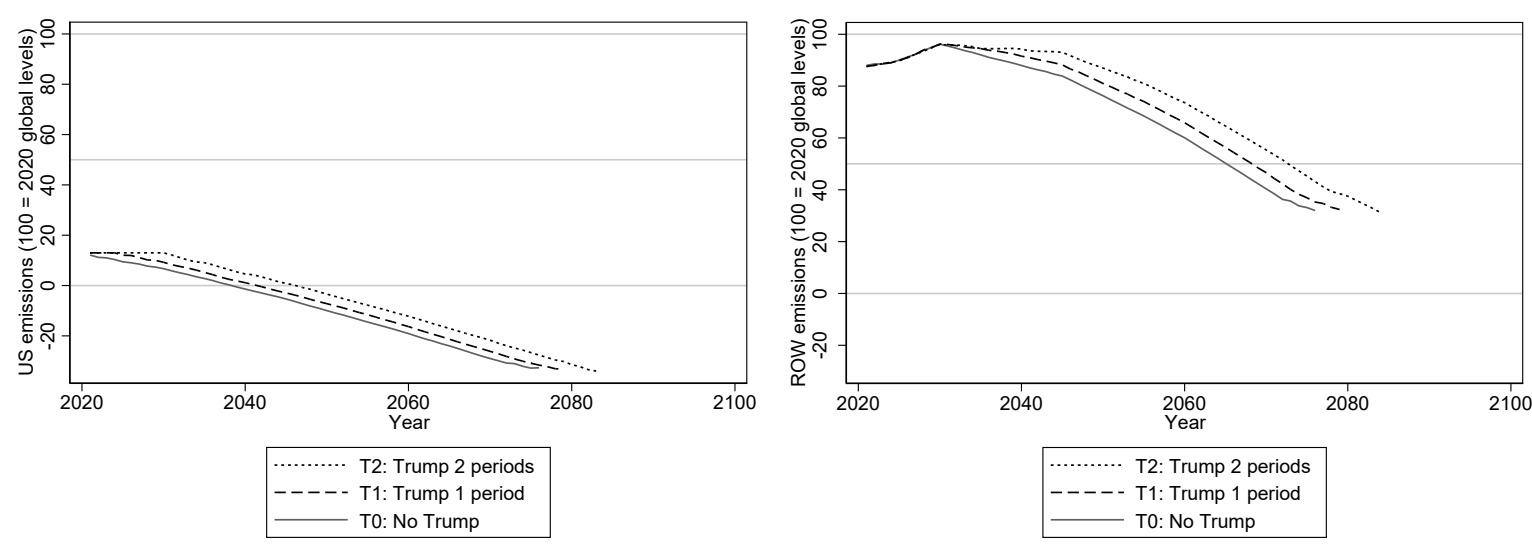

Paris aims to limit the global mean temperature rise to "well below $2^{\circ} \mathrm{C}$ above pre-industrial levels."

The remainder of our results focus on how Trump influences the prospects for achieving this goal.

The bottom two rows in Table 1 shows the shares of scenarios that limit aggregate emissions to within the bounds for the estimated $2^{\circ} \mathrm{C}$ budget (31-37 times current annual emissions), under our 
three treatments. Only a very small fraction of the scenarios meets the criteria, and US withdrawal reduces this fraction considerably. Notably, no scenario with the high-emissions version of current NDCs reaches the target (this cannot be seen from the table). Because overall, only .3\% (3295) scenarios result in emissions within the range of the budget estimate, we include all these scenarios in the remainder of the analysis, hence using the upper-bound of the remaining emissions budget estimate only, corresponding to the second row from bottom in Table 1. Thus, we adopt the least stringent interpretation of the Paris Agreement's goal (ignoring "well below" and the reference to $1.5^{\circ} \mathrm{C}$ ), as well as of the estimated budget for achieving this interpretation of the goal.

Table 1 (columns 3-8) presents the minimum values for other parameters in those scenarios that stay within the upper-bound estimate for the $2^{\circ} \mathrm{C}$ budget, conditional on treatment and the status of the progression principle. Across conditions, the most crucial parameter is the compliance rate, with a minimum value of $80-90 \%$. In contrast, the required confidence in global stocktake is much lower, especially under T0. Overall, Trump raises the minimum requirement for other criteria in many instances. For example, the first row shows that to compensate for each Trump term, other countries would need to unilaterally boost their NDCs' ambition level from 2020 onwards by more than one additional pp.

Important to note is that the values given in Table 1 constitute necessary but not sufficient conditions. The third row from bottom shows the percentage of scenarios where the conditions identified in the same row are simultaneously satisfied. These percentages are many times larger than those in the bottom two rows, which show the percentages of scenarios that stay within, respectively, the upper and lower bound for the $2^{\circ} \mathrm{C}$ budget estimate. Author (2020) provides a 
more detailed analysis of the conditions under which the $2^{\circ} \mathrm{C}$ is achieved, but only for the T1 scenario.

\section{Conclusions}

In this paper, we use a novel agent-based model to study how the US withdrawal influences the Paris climate cooperation process. We isolate the effect of this withdrawal by comparing three treatments - no US withdrawal (T0, baseline), US return to Paris after a single presidential period (T1), and US return after two presidential periods (T2) - while controlling for other factors. By operationalizing core elements of the Paris climate cooperation process in stylized form, the model enables us to study not only how the withdrawal might influence the prospects for achieving the agreement's temperature goals, but also how achieving these goals despite a US withdrawal would place more stringent requirements on other core elements of the Paris climate cooperation process. Our model thereby goes substantially beyond the received literature in terms of modeling strategy, interactive effects among countries within the architecture of the Paris Agreement, and the aspirational $2^{\circ} \mathrm{C}$ goal of the Paris Agreement.

Our results may be summarized as follows. First, the more responsive countries are to what others promise and deliver, the bigger the detrimental effect of a US withdrawal. With high responsiveness, a withdrawal will entail serious and long-term repercussions on other countries' willingness to contribute.

Second, the Trump effect is largest under assumptions about the Agreement's architecture that otherwise facilitate its effectiveness. We find that a strong review process that parties trust is particularly instrumental for the Agreement to be effective. It follows that the reduction in effectiveness due to Trump is larger the more parties trust the review process.

Third, under pessimistic assumptions about model parameters, global emissions may continue to grow for the rest of the century irrespective of Trump; however, a US withdrawal will cause emissions to become even higher than they would be otherwise. Under more optimistic assumptions 
concerning the controls, emissions will peak, then decline, and eventually reach zero. However, US withdrawal will cause the decline to come later than it would otherwise. For all treatments, our simulations suggest that reaching the $2^{\circ} \mathrm{C}$ target - let alone $1.5^{\circ} \mathrm{C}$ - will be extremely challenging. Indeed, these targets might have proved out of reach even without US withdrawal. Nevertheless, US withdrawal will further reduce the prospects for reaching them.

Fourth, our results provide interesting indications concerning potentially countervailing measures to compensate for Trump's inaction. For example, to reach the $2^{\circ} \mathrm{C}$ target despite a one-period US withdrawal, other countries must be willing to unilaterally reduce their emissions by at least one additional pp for every five-year period from 2025 onwards, compared to what is required without such a withdrawal. With a two-period withdrawal, the corresponding figure exceeds two pp. Similar requirements apply for other core parameters in the model, such as compliance and confidence in the global stocktake.

Finally, and unsurprisingly, a US withdrawal will quickly influence US emissions substantially, while having only a moderate immediate effect on other countries' emissions. Importantly, however, after about 20 years (i.e., from around 2040) the effect of the withdrawal on other countries' emissions will begin exceeding the effect on US emissions. Due to the Paris Agreement's emphasis on reciprocity, even temporary withdrawal by a major emitter will likely entail serious long-term repercussions on what other countries are prepared to contribute. Thus, Trump's unilateral "laggardship" reduces the prospects for reaching the $2^{\circ} \mathrm{C}$ target to near zero and will entail a substantial effect on long-run global emissions, even if the next president should re-enter the Agreement.

A limitation of the model is that it is based on several assumptions that cannot be calibrated using empirical data. For this reason, the Trump effect has been estimated across a range of different assumptions. As countries start to implement the Agreement, more data will become available for calibration. A future ex-post analysis would therefore be able to estimate the Trump effect with 
more confidence, using this model to compare it to the counterfactual scenario without US

withdrawal.

Another limitation is that the model excludes non-state and subnational state actors. It thus fails to

capture that many US companies and subnational governments have signaled a continued

commitment to the Paris Agreement. The Agreement embraces their actions, and the COP21

Decisions set out a larger role for such non-state actors in the future process, including through an

annual high-level meeting for announcement and follow-up of commitments (Hale 2016; Morgan and

Northrop 2017). However, Allan (2019) warns that non-state action is not a substitute for state action

and argues that states are required as drivers, implementers, and funders. The effect of non-state

action on the Paris Agreement's effectiveness is an important question for future research.

\section{References}

Allan, J.I. (2019) Dangerous Incrementalism of the Paris Agreement, Global environmental politics, 19

(1), 4-11.

Bang et al (2017)

Bardsley, N., \& Moffatt, P. G. (2007). The experimetrics of public goods: Inferring motivations from contributions. Theory and Decision, 62(2), 161-193.

Briner, G., \& Moarif, S. (2016). Unpacking provisions related to transparency of mitigation and support in the Paris Agreement. Climate Change Expert Group (Vol. 2016(2)). Paris: OECD/IEA.

Brun, A. (2016). Conference diplomacy: The making of the Paris Agreement. Politics and Governance, 4(3), 115-123.

Buchholz, W., Haslbeck, C., \& Sandler, T. (1998). When does partial co-operation pay? FinanzArchiv/Public Finance Analysis, 55(1), 1-20.

Buchholz, W., \& Sandler, T. (2016). The exploitation hypothesis in a public good economy: some extensions. CESifo Working Paper Series, 5717. Available at SSRN:

https://ssrn.com/abstract $=2737281$

Croson, R. T. (1996). Partners and strangers revisited. Economics Letters, 53(1), 25-32.

Clarke L., K. Jiang, et al. (2014) Assessing Transformation Pathways. In: Edenhofer, O., R. Pichs-

Madruga,Y. et al. (eds.). Climate Change 2014: Mitigation of Climate Change. Contribution of

Working Group III to the Fifth Assessment Report of the Intergovernmental Panel on Climate Change.

Cambridge, UK and New York, NY: Cambridge University Press.

Du Pont, Y. R., Jeffery, M. L., Gütschow, J., Rogelj, J., Christoff, P., \& Meinshausen, M. (2017). Equitable mitigation to achieve the Paris Agreement goals. Nature Climate Change, 7(1), 38. 
Falk, A. and U. Fischbacher. (2005) Modeling strong reciprocity. In: H. Gintis, S. Bowles, R. T. Boyd, et al. (eds.), Moral sentiments and material interests: The foundations of cooperation in economic life. Cambridge (MA): MIT Press.

Farmer, J.D. and D. Foley (2009) The economy needs agent-based modelling, Nature, 460 (7256), 685-686.

Fawcett, A. A., Iyer, G. C., Clarke, L. E., Edmonds, J. A., Hultman, N. E., McJeon, H. C., et al. (2015). Can Paris pledges avert severe climate change? science, 350(6265), 1168-1169.

Fischbacher, U., \& Gächter, S. (2010). Social preferences, beliefs, and the dynamics of free riding in public goods experiments. The American Economic Review, 100(1), 541-556.

Fischbacher, U., Gächter, S., \& Fehr, E. (2001). Are people conditionally cooperative? Evidence from a public goods experiment. Economics Letters, 71(3), 397-404.

Galik, C. S., DeCarolis, J. F., \& Fell, H. (2017). Evaluating the US mid-century strategy for deep decarbonization amidst early century uncertainty. Climate Policy, 17(8), 1046-1056.

Global Carbon Project. 2016. "Carbon Budget and Trends 2016", available from www.globalcarbonproject.org/carbonbudget (accessed 19.05.17).

Goodwin, P., Katavouta, A., Roussenov, V. M., Foster, G. L., Rohling, E. J., \& Williams, R. G. (2018). Pathways to $1.5^{\circ} \mathrm{C}$ and $2{ }^{\circ} \mathrm{C}$ warming based on observational and geological constraints. Nature Geoscience, 11(2), 102-107.

Güthschow, J., Jeffery, L., Giseke, R., \& Gebel, R. (2018). The PRIMAP-hist national historical emissions time series (1850-2015). V. 1.2. GFZ Data Services.,

Hale, T. (2016) "All hands on deck": The Paris agreement and nonstate climate action, Global environmental politics, 16 (3), 12-22.

Hoel, M. (1991). Global environmental problems: the effects of unilateral actions taken by one country. Journal of Environmental Economics and Management, 20(1), 55-70.

Hof, A.F., M.G. den Elzen, A. Admiraal, et al. (2017) Global and regional abatement costs of Nationally Determined Contributions (NDCs) and of enhanced action to levels well below $2 \mathrm{C}$ and $1.5 \mathrm{C}$, Environmental Science \& Policy, 71, 30-40.

Holtsmark, B. (2013). International cooperation on climate change: why is there so little progress? In R. Fouquet (Ed.), Handbook on Energy and Climate Change (pp. 327-343). Cheltenham, UK: Edward Elgar.

Holz, C., Kartha, S., \& Athanasiou, T. (2018). Fairly sharing 1.5: national fair shares of a $1.5^{\circ} \mathrm{C}-$ compliant global mitigation effort. International Environmental Agreements: Politics, Law and Economics, 18, 117-134.

Hovi et al (2017)

Höhne, N., Kuramochi, T., Warnecke, C., Röser, F., Fekete, H., Hagemann, M., et al. (2017). The Paris Agreement: resolving the inconsistency between global goals and national contributions. Climate Policy, 17(1), 16-32.

IEA (2016) World Energy Outlook 2016, Paris: OECD/IEA.

Kemp, L. (2017). Better out than in. Nature Climate Change, 7(7), 458.

Keser, C., \& Van Winden, F. (2000). Conditional cooperation and voluntary contributions to public goods. The Scandinavian Journal of Economics, 102(1), 23-39.

Kocher, M. G., Cherry, T., Kroll, S., Netzer, R. J., \& Sutter, M. (2008). Conditional cooperation on three continents. Economics Letters, 101(3), 175-178.

Konrad, K. A., \& Thum, M. (2014). Climate policy negotiations with incomplete information. Economica, 81(322), 244-256.

Meinshausen, M. (2016). Facts4COP21: Paris Agreement includes ambitious longterm goal. Available from http://www.climate-energy-college.net/facts4cop21-paris-agreement-includesambitious-long-term-goal Accessed 24.05.07.

Miller, J. H., \& Page, S. E. (2009). Complex adaptive systems: an introduction to computational models of social life. Princeton, NJ: Princeton University Press.

Morgan, J. and E. Northrop (2017) Will the Paris Agreement accelerate the pace of change?, Wiley Interdisciplinary Reviews: Climate Change, 8 (5), e471. 
Nyborg, K. (2018). Reciprocal climate negotiators. Journal of Environmental Economics and Management 92, 707-725.

Pan, X., den Elzen, M., Höhne, N., Teng, F. \& Wang, L. (2017). Exploring fair and ambitious mitigation contributions under the Paris Agreement goals, Environmental Science \& Policy 74(1): 49-56.

PBL (2017). PBL Climate Pledge INDC tool. Retrieved from http://infographics.pbl.nl/indc/ [Last access: 09.11.2017].

Pickering, J., McGee, J. S., Stephens, T., \& Karlsson-Vinkhuyzen, S. I. (2018). The impact of the US retreat from the Paris Agreement: Kyoto revisited? Climate Policy, 18(7), 818-827.

Rajamani, L. (2016). Ambition and differentiation in the 2015 Paris Agreement: Interpretative possibilities and underlying politics. International and Comparative Law Quarterly, 65(2), 493514.

Rajamani, L., \& Guerin, E. (2017). Central Concepts in the Paris Agreement and How They Evolved. In D. R. Klein, M. P. Carazo, M. Doelle, J. Bulmer, \& A. Higham (Eds.), The Paris Agreement on Climate Change. Analysis and Commentary (pp. 74-90). Oxford: Oxford University Press.

Rogelj, J., Den Elzen, M., Höhne, N., Fransen, T., Fekete, H., Winkler, H., et al. (2016). Paris Agreement climate proposals need a boost to keep warming well below 2 C. Nature, 534(7609), 631-639.

Rogelj, Joeri, Oliver Fricko, Malte Meinshausen, Volker Krey, Johanna JJ Zilliacus and Keywan Riahi. (2017). Understanding the origin of Paris Agreement emission uncertainties. Nature Communications 815748.

Sanderson, B. M., \& Knutti, R. (2016). Delays in US mitigation could rule out Paris targets. Nature Climate Change, 7(2), 92.

Sprinz, D. F., Sælen, H., Underdal, A., \& Hovi, J. (2018). The effectiveness of climate clubs under Donald Trump. Climate policy, 18(7), 828-838.

UNFCCC (2015). FCCC/CP/2015/L.9.

UNFCCC (2016). FCCC/CP/2016/10/Add.1

UNFCCC. (2019a). FCCC/PA/CMA/2018/3/Add.1.

UNFCCC. (2019b). FCCC/PA/CMA/2018/3/Add.2.

Urpelainen, J., \& Van de Graaf, T. (2018). United States non-cooperation and the Paris agreement. Climate Policy, 18(7), 839-851. 


\section{Appendix: Model explanation and pseudocode}

Table A.1: Model parameters and variables.

\begin{tabular}{|c|c|c|}
\hline $\begin{array}{l}\text { Variable or } \\
\text { parameter }^{17}\end{array}$ & Explanation & $\begin{array}{c}\text { Measurement } \\
\text { units / range/ } \\
\text { options }\end{array}$ \\
\hline \multicolumn{3}{|c|}{ Agent-specific input parameters } \\
\hline $\begin{array}{l}\text { Initial } \\
\text { emissions } \\
\left(\mathbf{e}_{\mathrm{i} 2020}\right)\end{array}$ & $\begin{array}{l}\text { Emissions in 2020. Assumed to equal } 2015 \text { emissions estimates by } \\
\text { Gütschow et al (2018). }\end{array}$ & Share of global \\
\hline $\begin{array}{l}\text { Initial } \\
\text { Willingness to } \\
\text { Contribute } \\
\text { (IWTC })\end{array}$ & Willingness to reduce emissions in the first 5-year contribution period & $\%$ of $\mathbf{e}_{i 2020}$ \\
\hline $\begin{array}{l}\text { Compliance } \\
\text { rate }_{i}\end{array}$ & Probability that $i$ will comply with its NDC in any given year & {$[0,1]$} \\
\hline $\begin{array}{l}\text { Reciprocity } \\
\text { Parameter (RP })\end{array}$ & $\begin{array}{l}\text { Willingness to reciprocate actions by others. The } \% \text { increase in i's } \\
\text { ambition in response to } 1 \% \text { increase in other parties' ambition. }\end{array}$ & {$[0,1]$} \\
\hline \multicolumn{3}{|c|}{ Agent-specific variables derived in the model } \\
\hline$N D C_{i t}$ & $\begin{array}{l}\text { Emission reductions pledged by } i \text { in a five-year contribution period } \\
\text { ending in } t\end{array}$ & $\%$ of $\mathbf{e}_{i 2020}$ \\
\hline$n d c_{i t}$ & Emissions reductions in year $t$ derived from $N D C_{i t}$ & $\%$ of $\mathbf{e}_{i 2020}$ \\
\hline $\begin{array}{l}\text { Contribution } \\
\left(c_{i t}\right)\end{array}$ & Delivered emissions reductions by $i$ in year $t$ & $\%$ of $\mathbf{e}_{i 2020}$ \\
\hline Emissions $\left(e_{i t}\right)$ & Emissions by $i$ in year $t$ & $\%$ of $\mathbf{e}_{i 2020}$ \\
\hline $\begin{array}{l}\text { Credibility } \\
\left(\text { cred }_{i}\right)\end{array}$ & $\begin{array}{l}\text { The weight given by other Parties to } N D C_{i} \text { when determining their } \\
\text { own } N D C\end{array}$ & {$[0,1]$} \\
\hline stock $_{i t}$ & $\begin{array}{l}\text { The emissions reductions realized by all other Parties in the period } \\
\text { assessed by the last global stocktake, as perceived by } i \text {. }\end{array}$ & $\begin{array}{c}\text { \% of global } \\
\text { emissions in } \\
2020 \text { excluding } \\
\mathbf{e}_{i 2020} \\
\end{array}$ \\
\hline \multicolumn{3}{|c|}{ Global input parameters } \\
\hline $\begin{array}{l}\text { Confidence in } \\
\text { Review (CiR) }\end{array}$ & $\begin{array}{l}\text { Factor by which Parties discount the outcome of reviews of other } \\
\text { Parties compliance. }\end{array}$ & {$[0,1]$} \\
\hline $\begin{array}{l}\text { Confidence in } \\
\text { Stocktake (CiS) }\end{array}$ & $\begin{array}{l}\text { Factor by which Parties discount the outcome of the global stocktake } \\
\text { of aggregate process. }\end{array}$ & {$[0,1]$} \\
\hline $\begin{array}{l}\text { Compliance } \\
\text { rate mean }\end{array}$ & Mean of uniform distribution of compliance rates across Parties. & {$[0,1]$} \\
\hline $\begin{array}{l}\text { Compliance } \\
\text { rate range }\end{array}$ & Range of uniform distribution of compliance rates across Parties. & {$[0,1]^{18}$} \\
\hline RP mean & $\begin{array}{l}\text { Mean of uniform distribution of Reciprocity Parameters across } \\
\text { Parties. }\end{array}$ & {$[0,1]$} \\
\hline RP range & $\begin{array}{l}\text { Range of uniform distribution of Reciprocity Parameters across } \\
\text { Parties. }\end{array}$ & {$[0,1]^{16}$} \\
\hline Boost2020 & $\begin{array}{l}\text { Increase in IWTC when Parties in } 2020 \text { submit/revise/confirm NDCs } \\
\text { with targets for } 2030\end{array}$ & $\begin{array}{c}\text { \% of global } \\
\text { emissions in } \\
2020\end{array}$ \\
\hline $\begin{array}{l}\text { Progression } \\
\text { principle }\end{array}$ & $\begin{array}{l}\text { Whether the progression principle (Paris Agreement Article } 3 \text { ) is } \\
\text { respected. }\end{array}$ & True; False \\
\hline
\end{tabular}

\footnotetext{
${ }^{17}$ Input parameters are shown in bold while endogenous variables are italicized.

${ }^{18}$ In the current analysis, set to .2, except when the mean is 0 or 1 meaning the range must be 0 .
} 


\begin{tabular}{|l|l|c|}
\hline NDC scenario & $\begin{array}{l}\text { Whether the high emissions / unconditional or low emissions / } \\
\text { conditional interpretation of first round NDCs is used. }\end{array}$ & High; Low \\
\hline $\begin{array}{l}\text { Learning } \\
\text { parameter }\end{array}$ & $\begin{array}{l}\text { Weight given to outcome of last review when assessing other } \\
\text { Parties' credibility }\end{array}$ & {$[0,1]$} \\
\hline
\end{tabular}

\section{Initialization}

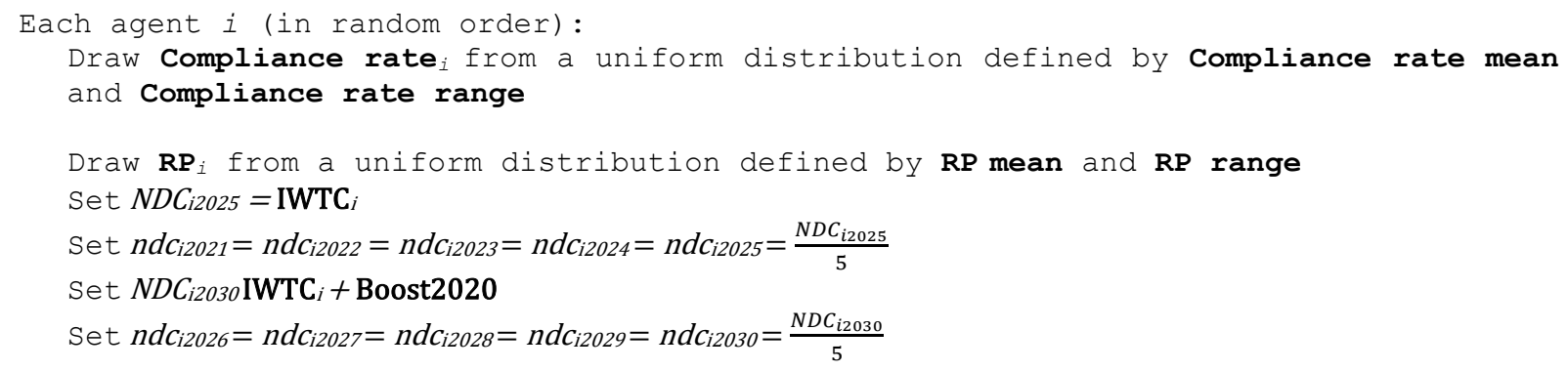

\section{Sequence}

Table A.2: Model sequence.

\begin{tabular}{|l|l|}
\hline 2021 & Contribution procedure \\
\hline 2022 & Contribution procedure \\
\hline 2023 & Contribution procedure \\
\hline & Global stocktake (assesses 2021 and 2022) \\
\hline Loop from $t=2025$ & Contribution procedure \\
\hline$t$ & Contribution procedure \\
\hline & Review implementation in $t-4$ and $t-3$ \\
\hline & Pledging procedure (for period $t+6$ to $t+10)$ \\
\hline$t+1$ & Contribution procedure \\
\hline$t+2$ & Contribution procedure \\
\hline & Review implementation in $t-2$ and $t-1$ \\
\hline$t+3$ & Contribution procedure \\
\hline & Global stocktake (assesses $t-2$ to $t+2)$ \\
\hline & Contribution procedure \\
\hline$t+5$ & Review implementation in $t$ and $t+1$ \\
\hline & Contribution procedure \\
\hline$t+6$ & Pledging procedure (for period $t+11$ to $t+15)$ \\
\hline & Contribution procedure \\
\hline$t+7$ & Review implementation in $t+2$ and $t+3$ \\
\hline$t+8$ & Contribution procedure \\
\hline & Contribution procedure \\
\hline & Global stocktake (assesses $t+3$ to $t+7$ ) \\
\hline$t+9$ & Review implementation in $t+4$ and $t+5$ \\
\hline & Contribution procedure \\
\hline
\end{tabular}

\section{Procedures}

\section{Pledging Procedure \\ If Progression principle $=$ False: $\mathrm{Loop}^{19}$ :}

${ }^{19}$ Parties sequentially set an indicated NDC, which is a function of others' indicated NDCs. 


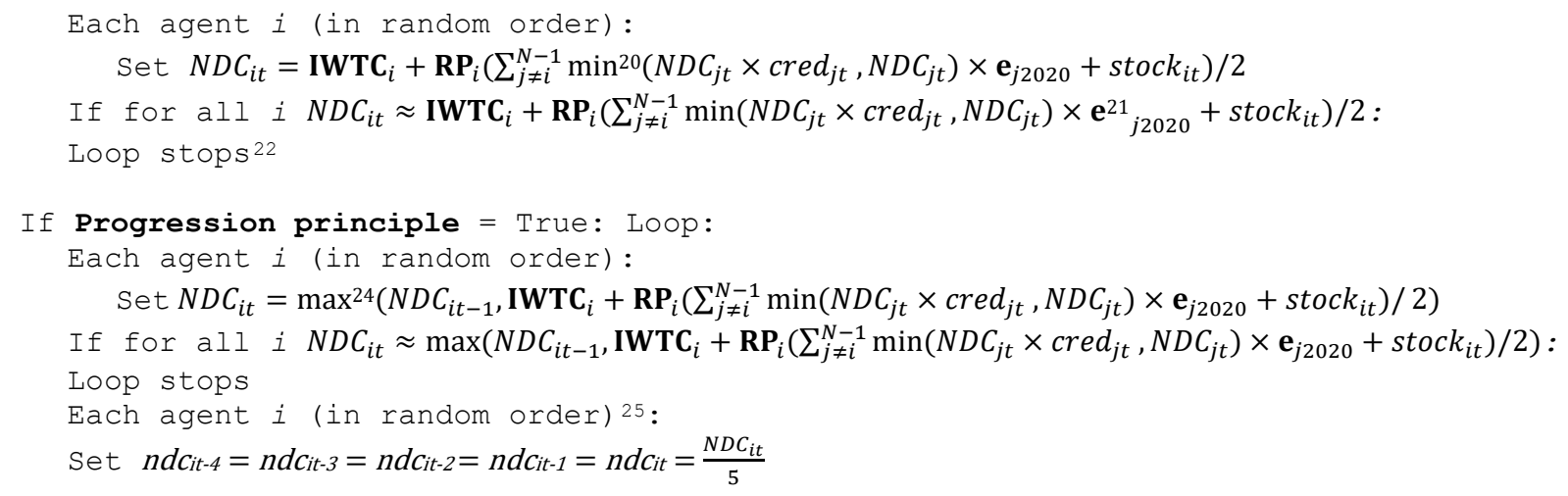

\section{Contribution Procedure 26}

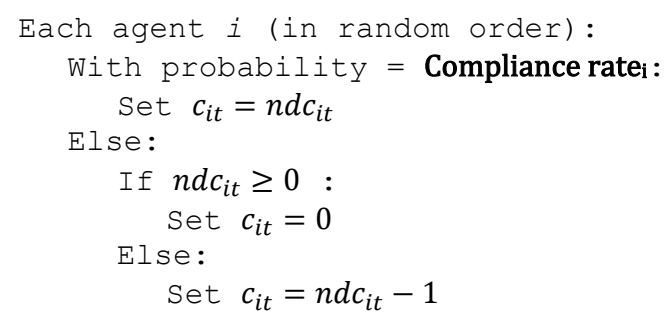

\section{Review}

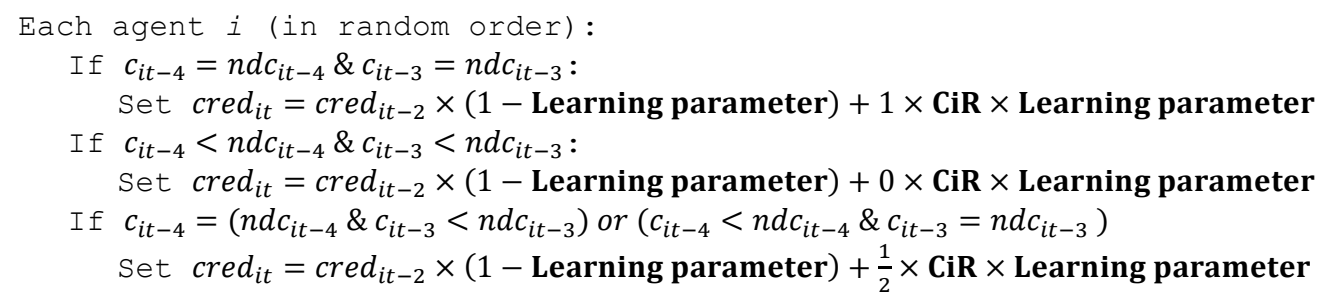

\section{Global stocktake}

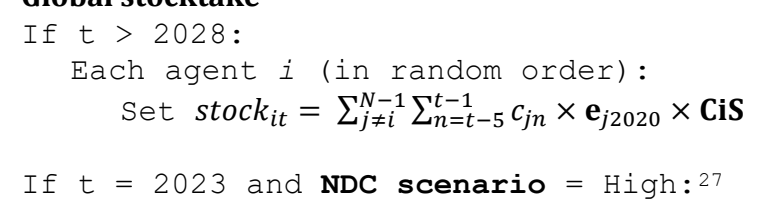
${ }^{20}$ The min function means that pledges to increase emissions (negative NDCs) are not discounted by credibility.
${ }^{21} e_{j}$ is $j$ 's share of global emissions excluding $e_{i}$
${ }^{22}$ When no party wants to revise its NDC given the NDCs indicated by others, the NDCs are finalized. [To limit computation time, NDCs are finalized when no country would want to change their indicative NDC by more than $.1 \mathrm{ppt}$. This simplification has a negligible effect on results.

${ }^{24}$ The max function ensures i's new NDC is no less ambitious than its previous NDC.

${ }^{25}$ The NDC is translated into annual emissions reductions, through linear interpolation.

${ }^{26}$ With probability Compliance rate $_{i}, i$ complies with its NDC. Non-complying agents contribute zero emissions reductions if they had pledged to reduce emissions, and increase emissions by 1 pp more than they had pledged if they had pledged increasing emissions

${ }^{27}$ In the first stocktake, only two years of implementation are assessed. The 5/2 multiplier normalizes the result to be comparable with 5 -year periods. Furthermore, the results are compared to a scenario with policies that were in place before the first NDCs were announced. As noted, first-round NDCs are estimated to keep global emissions constant in 2020-2025. However, compared to a scenario derived from policies in place before the 


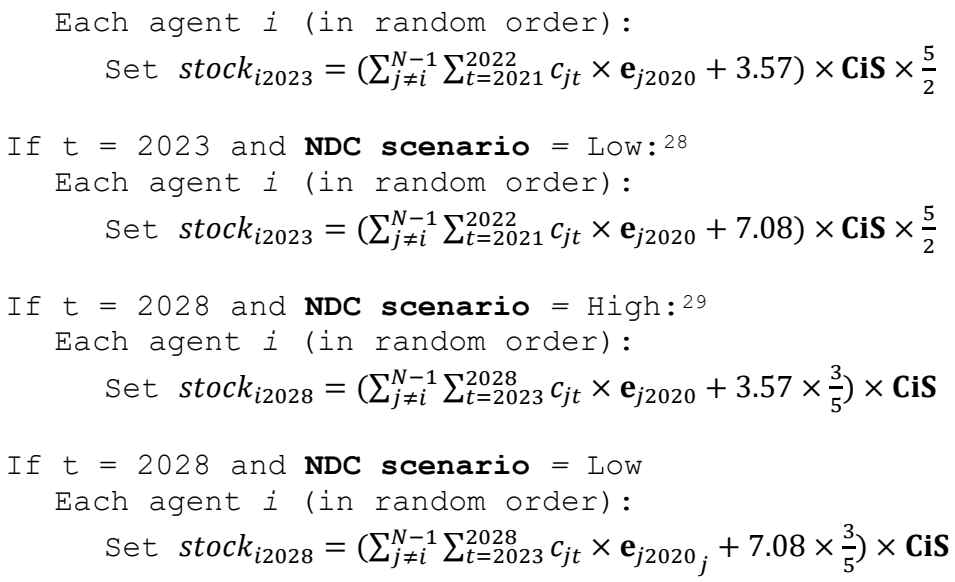

Adjustments for Trump for one presidential term

\section{Contribution Procedure}

If $t \leq 2024: 30$

Set CUSA,t $=0$

\section{Adjustments for Trump for two presidential terms}

\section{Pledging Procedure}

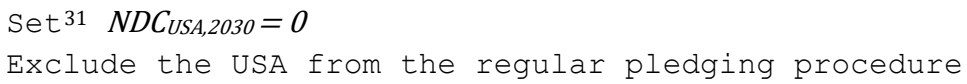

\section{Contribution Procedure}

If $t \leq 2030$ :

$$
\text { Set }{ }^{32} c_{U S A, t}=0
$$

\section{Review}

$$
\text { If } \begin{aligned}
t \leq & 2033 \\
& \operatorname{set}^{33} \operatorname{cred}_{U S A, t}=0
\end{aligned}
$$

NDCs were announced, unconditional NDCs reduce emissions by 3.57\% (Rogelj et al 2016, Supplementary Table 5), hence $3.57 \mathrm{pp}$ is added.

\footnotetext{
28 In the low emissions scenario, NDCs reduce emissions by $7.08 \mathrm{pp}$ relative to a to a scenario with policies that were in place before the first NDCs were announced (Rogelj et al 2016, Supplementary Table 5).

${ }^{29}$ The second stocktake includes the years 2023-2025, in which emissions are compared to a scenario with policies that were in place before the first NDCs were announced.

${ }^{30}$ Action by the USA is delayed by four years.

31 If the USA is out of the Agreement in 2020, other countries will perceive it as if the USA promised to make zero emissions reductions until 2030.

${ }^{32}$ The USA delivers no emissions reductions until 2030.

${ }^{33}$ Ensures the USA's credibility stays at zero until and including the review in 2033, which assesses contributions in 2029 and 2030.
} 